\title{
AS BRECHAS DA CIDADE: A PRAÇA DE BOLSO DO CICLISTA DA CIDADE DE CURITIBA, PARANÁ
}

\author{
THE CRACKS OF THE CITY: THE "PRAÇA DE BOLSO DO CICLISTA" IN \\ CURITIBA, BRAZIL
}

LAS BRECHAS DE LA CIUDAD: LA "PRAÇA DE BOLSO DO CICLISTA" DE LA

CIUDAD DE CURITIBA, PARANÁ

Daniella Tschöke Santana*, Simone Rechia*, Emília Amélia Pinto Costa Rodrigues*

Palavras chave:

Centros de convivência e lazer.

Cidade.

Área urbana.
Resumo: Este artigo discorre sobre a tipologia espacial dos espaços públicos urbanos de pequena escala, os pocket parks, a partir da experiência da construção da Praça de Bolso do Ciclista (PBC), espaço idealizado por um grupo de ciclistas de Curitiba, capital do Paraná. É um estudo de caso de cunho qualitativo que utilizou como instrumentos metodológicos documentos de diversas fontes, observações, registros fotográficos e entrevistas semiestruturadas, cujos dados foram reunidos, sistematizados e triangulados. A PBC foi fruto de uma parceria entre poder público e cidadãos, que construíram a praça em regime de mutirões nos fins de semana. A partir de uma ação comunitária, um pequeno espaço que busca promover a cultura da bicicleta e intensificação de seu uso foi concretizado. Indo além, questões urbanas e políticas significativas também foram levantadas, especialmente a ação política de dimensão comunitária, a humanização e democratização da cidade, a partir da ação em seus espaços.

\section{Keywords:}

Living and leisure centers.

City.

Urban area.
Abstract: This article discusses the spatial typology of small-scale urban public spaces known as pocket parks, based on the experience of building the "Praça de Bolso do Ciclista" or PBC (cyclist's pocket square), a space designed by a group of cyclists from Curitiba, Paraná, Brazil. This is a qualitative case study whose methodological tools include documents from distinct sources, observations, photographs and semi-structured interviews. Data were gathered, systematised and triangulated. The PBC was the result of a partnership between government and citizens, who built the square out of collective efforts on weekends. Based on community action, a small space was built to promote bicycle culture and increase its use. Furthermore, significant urban and political issues were also raised, especially community political action, humanization and democratization of the city after the action in its areas.
Palabras clave: Centros de ocio y convivencia.

Ciudad.

Área urbana.
Resumen: En este artículo se analiza la tipología espacial de los espacios públicos urbanos de pequeña escala, conocidos como pocket parks, a partir de la experiencia de la construcción de la "Praça de Bolso do Ciclista" (PBC), espacio idealizado por un grupo de ciclistas de Curitiba/PR. Se trata de un estudio de caso con carácter cualitativo que ha utilizado como herramientas metodológicas documentos de diversas fuentes, observaciones, registros fotográficos y entrevistas semiestructuradas. Los datos fueron recopilados, sistematizados y triangulados. La PBC fue el resultado de una asociación entre el poder público y los ciudadanos, quienes construyeron la plaza con trabajo voluntario en los fines de semana. A partir de la acción comunitaria se ha logrado un pequeño espacio que busca promover la cultura de la bicicleta y la intensificación de su uso. Además, también se plantearon importantes cuestiones urbanas y políticas, especialmente la acción política de dimensión comunitaria, la humanización y democratización de la ciudad, a partir de la acción en sus espacios.
*Universidade Federal do Paraná. Curitiba, PR, Brasil.

E-mail: dani_ellats@hotmail.com

Recebido em: 25-07-2016 Aprovado em: 28-12-2016

(c) (1) (8) Licence 


\section{INTRODUÇÃO}

O planejamento urbano de ideais modernistas, dominantes especialmente na década de 1960, e a concomitante "invasão" dos automóveis, principalmente nos grandes centros urbanos, modificaram as formas de organização, construção e apropriação da cidade e seus espaços. Para Gehl (2015), o desenvolvimento de um cenário cada vez mais racional, individualista e simplificado e o aumento exacerbado de automóveis contribuíram significativamente para que o espaço urbano fosse gradualmente perdendo a oportunidade de funcionar efetivamente como ponto de encontro de pessoas; consequentemente, suas funções culturais, sociais e de expressão da dimensão humana no ambiente urbano tornaram-se cada vez mais sitiadas.

No contexto brasileiro, por causa da progressiva limitação de espaços livres públicos nas regiões mais densas das cidades e, ao mesmo tempo, a crescente demanda por espaços disponíveis para serem usufruídos pela população, os pequenos espaços livres urbanos constituem-se uma tipologia espacial que vem ganhando importância no cenário da cidade. Esses potenciais pequenos espaços cumprem diferentes funções, conectadas fortemente ao contexto em que estão inseridas e às demandas locais específicas, mas a maioria é destinada a experiências de lazer. Por se tratar de intervenções feitas em pequena escala, geralmente não exigem grandes investimentos econômicos/urbanísticos (WEISHOF, 2014) e vêm sendo valorizados e considerados alternativas interessantes e viáveis que podem contribuir para melhorar a qualidade de vida da população, principalmente de habitantes que moram/trabalham em regiões de grande densidade, tanto populacional quanto de edificações.

Aponta-se a necessidade cada vez mais evidente de fomento ao desenvolvimento de espaços públicos de lazer e experiências nesse âmbito, na perspectiva do exercício da cidadania, tempo/espaço no qual o ser humano tem a possibilidade de realizar ações que promovam e influenciem seu cotidiano, transformando o mundo ao seu redor.

A tensão entre a atual falta de espaço no coração das cidades e, em contrapartida, a necessidade de espaços públicos como uma das possibilidades de ressaltar a vida social urbana faz emergir os pequenos espaços urbanos enquanto brechas, com potencial para ampliar as possibilidades de convivência interpessoal e estimular a apropriação do meio urbano. Neste caso, os pocket parks podem ser considerados uma dessas brechas.

A criação de pequenos espaços nas áreas de grande concentração de pessoas e construções das cidades é uma prática comum principalmente em cidades americanas, que chamam esses locais de pocket parks ou vest-pocket parks, denominações que podem ser traduzidas como espaços "de bolso". Na década de 1960, por haver uma densa área construída na região de Manhattan, em Nova York, e a necessidade da criação de espaços livres públicos na cidade, com vistas à melhoria da qualidade de vida da população, foi discutida a criação de áreas dedicadas aos trabalhadores e lojistas da região, que as utilizariam em seus intervalos de trabalho (PAGNONCELLI, 2012).

Conforme afirma Blake (2016), os pocket parks são caracterizados por serem espaços urbanos abertos em uma área de pequena escala. Apresentam dimensões normalmente variáveis, dependendo do espaço disponível, das demandas da região do entorno e do entendimento de cada cidade a respeito das características dessa tipologia, uma vez que ainda não há conhecimento acerca de uma padronização ou metragem de referência que designe um espaço como pocket park ou "de bolso". 
Mesmo com as especificidades das cidades que idealizam e implantam os pocket parks, duas propriedades gerais para a caracterização desse tipo de espaço parecem ser mais relevantes: a questão da pequena dimensão física do local e o aproveitamento de áreas subutilizadas, a partir da transformação de remanescentes urbanos abandonados, comumente situados em áreas densas das cidades (WEISHOF, 2014).

A literatura a respeito dessa forma de organização do espaço ainda não está consolidada, no entanto, as experiências com os pocket parks em várias cidades, principalmente americanas, têm estes pequenos locais de tamanho variável e de uso público comumente localizados em áreas privadas (inteiramente ou porções), cujas funções estão conectadas com o contexto do entorno, constituindo pequenos espaços de eventos, áreas infantis, espaços de encontro, "estar", descanso, dentre outras (PAGNONCELLI, 2012; WHEISHOF, 2014; BLAKE, 2016).

A localização dos pocket parks, em locais privados ou públicos, é uma variável importante, pois tende a influenciar tanto fases de projeto e construção como também as formas de apropriação desses locais. Na cidade de Curitiba, capital do Paraná, alternativamente à lógica mais comum, a Praça de Bolso do Ciclista está localizada em um terreno público da cidade.

Segundo Blake (2006), muitos parques e praças de bolso podem ser resultado de um esforço comunitário, de entidades privadas ou ainda de associações reivindicando as áreas em favor da vizinhança local. Podem ser igualmente fruto de "[...] parceria público-privada, através de instituições, associações vicinais, empresas - assumindo a responsabilidade de gestão e manutenção, e por vezes até de projeto e execução" (WEISHOF, 2014, p. 45).

Percebe-se que cidades de diversas regiões do mundo vêm compreendendo o potencial que os pequenos espaços livres, principalmente os localizados entre edifícios, podem oferecer. Dessa forma, esses espaços pequenos, vazios, esquecidos ou subutilizados, e que não apresentam o valor de troca ${ }^{1}$ preconizado no espaço atual das cidades (ou seja, improdutivos financeiramente), podem ganhar vida ao se tornarem espaços urbanos que potencializam vivências, em sua maioria, de lazer.

Este artigo pretende discorrer a respeito dessa tipologia espacial emergente, a dos espaços públicos urbanos de pequena escala, tendo como base a experiência da construção da Praça de Bolso do Ciclista (PBC), um espaço idealizado por um grupo de ciclistas da cidade de Curitiba e construído com o apoio da comunidade e da prefeitura.

\section{METODOLOGIA}

Trata-se de uma pesquisa de abordagem qualitativa. De acordo com Minayo (2011), trabalha com significados, motivos, aspirações, crenças, valores e atitudes, respondendo a questões muito particulares da realidade, de modo que esta não possa ou não deva ser quantificada. Também pode ser definida como um estudo de caso, pois "[...] surge do desejo de entender fenômenos sociais complexos e [...] permite que os investigadores foquem um "caso" e retenham uma perspectiva holística e do mundo real - como no estudo de ciclos individuais da vida, organização de pequenos grupos [...]" (YIN, 2015, p. 4).

\footnotetext{
1 Lefebvre (2001) distingue "o valor de uso (a cidade e a vida urbana, o tempo urbano) e o valor de troca (os espaços comprados e vendidos, o consumo dos produtos, dos bens dos lugares e dos signos)" (p. 35). Também aponta que "a própria cidade é uma obra, e esta característica contrasta com a orientação irreversível na direção do dinheiro, na direção do comércio, na direção das trocas, na direção dos produtos. Com efeito, a obra é o valor de uso e o produto é valor de troca" (p. 12).
} 
Para a exploração do tema foram utilizados os seguintes instrumentos: documentos de diversas fontes (materiais midiáticos on-line ${ }^{2}$ - tais como artigos de jornais, fotos e conteúdos postados em redes sociais - e documentos oficiais), roteiro de observação (13 observações, com duração média de duas horas cada uma, nos três períodos do dia, em dias úteis e fins de semana), registros de imagem e roteiro de entrevistas semiestruturadas.

Foram entrevistadas 24 pessoas (cinco frequentadores da praça; dez donos de estabelecimentos e moradores do entorno; três integrantes da associação de ciclistas; três voluntários que ajudaram no processo de construção da PBC; três gestores da Prefeitura Municipal de Curitiba - PMC). Participaram do estudo pessoas de ambos os sexos, com mais de 18 anos. Antes da entrevista, todos os participantes receberam e assinaram um Termo de Consentimento Livre e Esclarecido.

Foram comparados os dados obtidos a partir do material midiático e nos documentos levantados às observações, entrevistas e aos registros de imagem, a fim de investigar se as partes envolvidas possuem compreensão similar ou diferenciada nas diversas fases do processo.

Essa abordagem auxilia na análise das várias vertentes que um objeto de pesquisa pode apresentar e diminui a possibilidade de "[...] adotar procedimentos que ressaltem apenas um aspecto do objeto em estudo [...]" (GÜNTHER et al., 2011, p. 241-242). Dessa forma, depois de analisados, os dados advindos dos diferentes métodos foram integrados, para serem identificados possíveis pontos de convergência ou divergência. A partir das informações correlacionadas, foram elaboradas, indutivamente, reflexões acerca da temática. Posteriormente, foi elaborada uma análise interpretativa acerca do processo de implementação da PBC.

Este estudo foi aprovado pelo Comitê de Ética em Pesquisa da Saúde da Universidade Federal do Paraná, sob o número de registro CAAE 48211015.2.0000.0102, conforme a resolução no 466/12 do Conselho Nacional de Saúde (BRASIL, 2013).

\section{A PRAÇA DE BOLSO DO CICLISTA DA CIDADE DE CURITIBA, PARANÁ}

A PBC (Figuras 1 e 2) fica na região central da cidade de Curitiba. Inaugurada em 2014, essa praça pública possui uma área de $127 \mathrm{~m}^{2}$ e situa-se no marco zero da Rua São Francisco - uma ruela de mão única, revitalizada em 2012 pela prefeitura, que possui diversos estabelecimentos comerciais e alguns prédios residenciais -, esquina com a Rua Presidente Faria - rua de mão dupla em que há considerável movimento de pedestres, ônibus e carros, principalmente durante a semana, cujo entorno possui prédios residenciais e comerciais, lojas, etc. A PBC situa-se, em um trajeto a pé, próxima a locais de interesse da cidade (Catedral Basílica; Passeio Público; Teatro Guaíra; Praça Santos Andrade, onde se localiza um dos campi da Universidade Federal do Paraná; Rua XV de Novembro, tradicional rua comercial que reúne grande número de pessoas).

Seu mobiliário é constituído de dois bancos de madeira, uma mureta de pedra central, um banco de superadobe ${ }^{3}$ revestido de mosaicos, quatro paraciclos, um "minipalco" de pedras redondo, um muro histórico e uma tela ao ar livre (área pintada de branco, no alto da parede do prédio contíguo à praça, que permite projeções multimídia), além de uma lixeira e iluminação, com dois postes situados no interior da praça. A calçada é uma mescla de concregrama, piso de

2 Foram utilizadas principalmente as notícias veiculadas pela Agência de Notícias da Prefeitura Municipal de Curitiba, por ser um importante canal de comunicação da Prefeitura, e pela Gazeta do Povo, por se tratar de um jornal de grande circulação na cidade.

3 Técnica de bioconstrução que utiliza terra comprimida em sacos para criar estruturas como paredes, bancos, coberturas. 
concreto ecológico que possibilita o plantio de grama no interior e permite a drenagem do solo, e petit pavet, calçamento de origem portuguesa, composto de pequenas pedras manualmente colocadas, ligado à memória cultural e urbanística de Curitiba, encontrado principalmente no centro da cidade.

Figura 1 - Praça de Bolso do Ciclista, em Curitiba

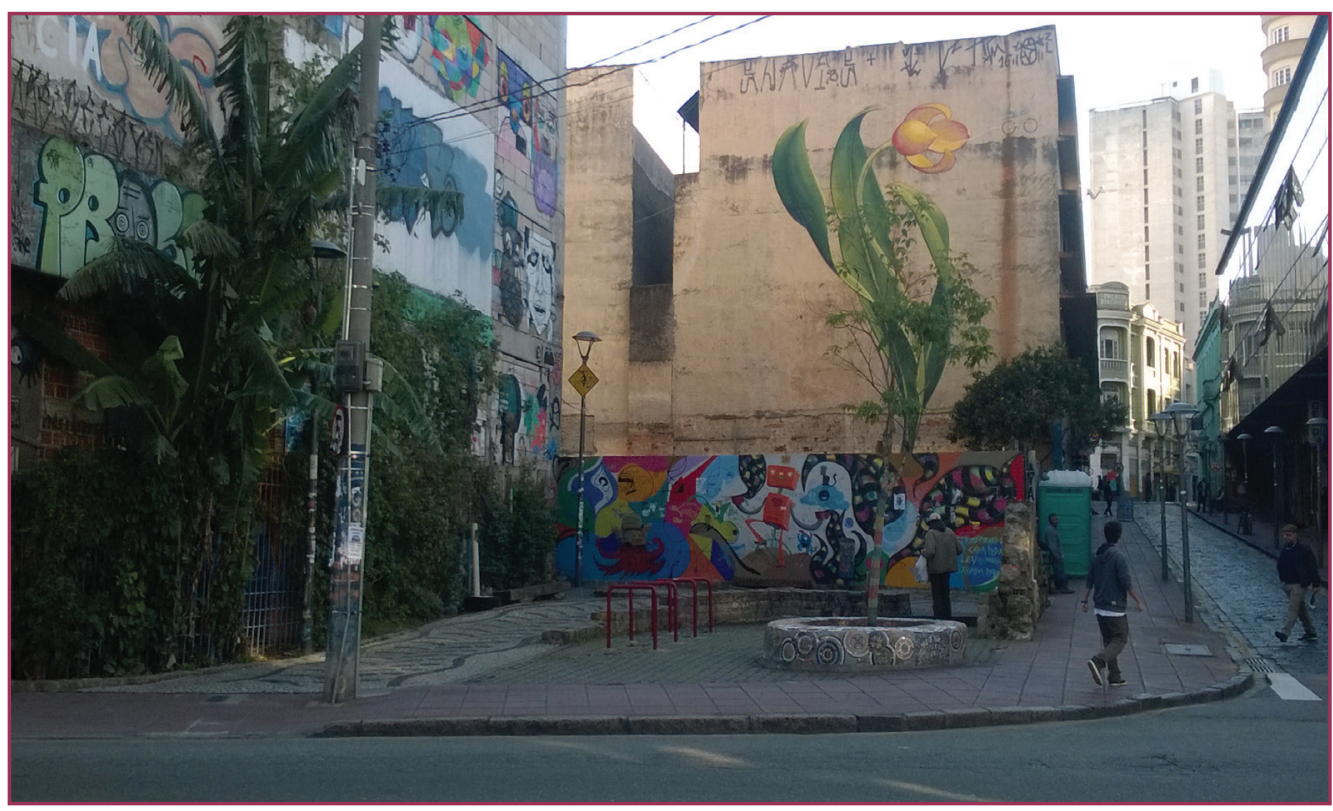

Fonte: Arquivo pessoal, 2016.

Figura 2 - Praça de Bolso do Ciclista, em Curitiba

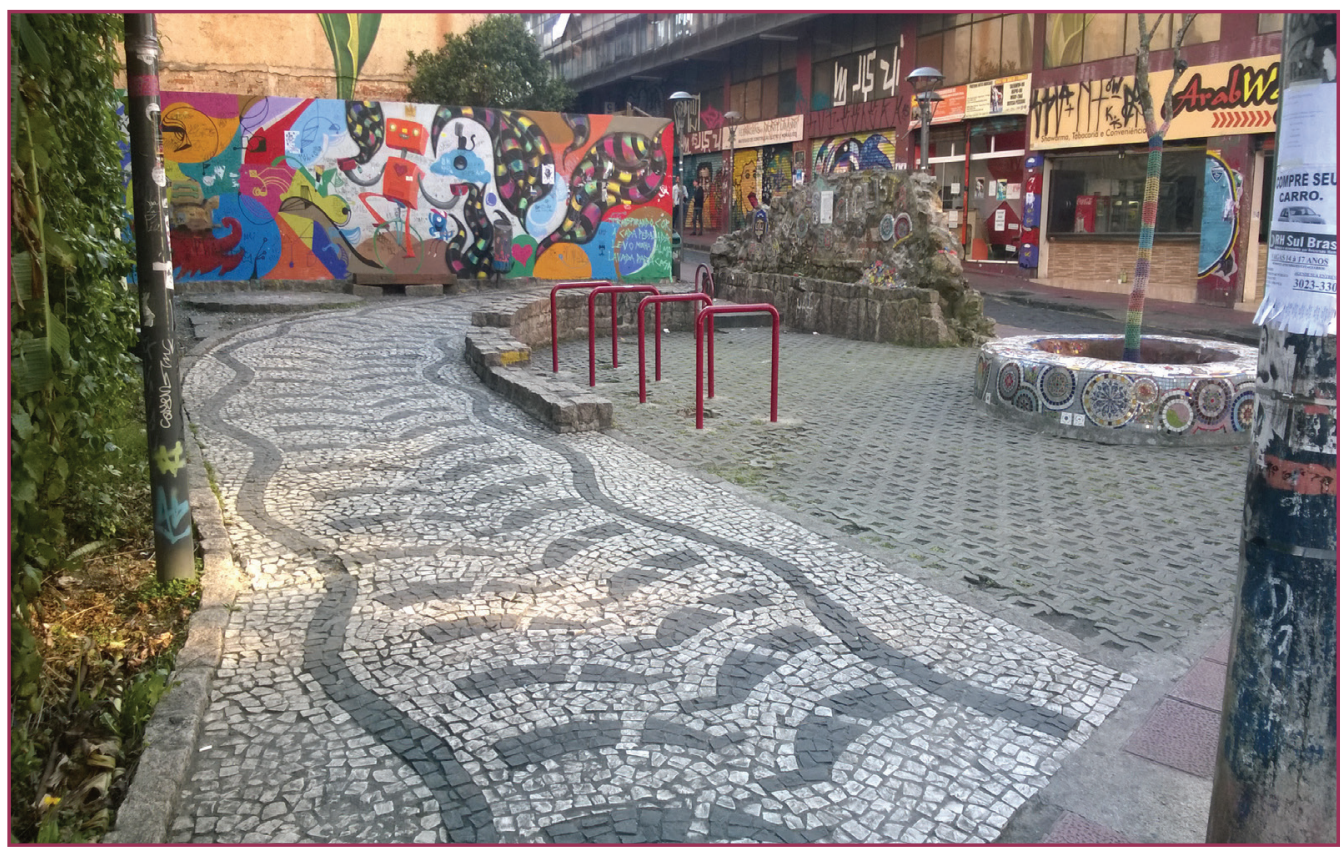

Fonte: Arquivo pessoal, 2016.

\subsection{Idealização, planejamento e projeto}

A PBC foi idealizada por um grupo de cicloativistas, dos quais grande parte era integrante da Ciclolguaçu, a Associação de Ciclistas do Alto Iguaçu. ${ }^{4} \mathrm{~A}$ sede da associação

4 Fundada com a intenção de consolidar o desenvolvimento de políticas de ciclomobilidade, a partir de uma interface de diálogo construtivo com o poder público. 
funciona no mesmo endereço da Bicicletaria Cultural, um empreendimento privado de apoio ao ciclista urbano. As duas organizações buscam trabalhar de forma mútua e complementar, a partir da temática da bicicleta na cidade.

Em frente à sede desses grupos havia um terreno vazio e inutilizado. Em 2011, a partir de conversas entre membros das duas instituições, foi levantada a possibilidade de o local tornarse uma praça, e que fosse do ciclista, em função da iniciativa ter partido de pessoas, instituições e espaços representativos da mobilidade por bicicleta. Em seguida, a partir de informações levantadas em órgãos municipais a respeito da situação daquele espaço, foi verificado que parte do terreno era da prefeitura e outra parte pertencia a uma massa falida ${ }^{5}$ contígua.

Os cicloativistas então solicitaram à prefeitura a construção da praça na porção municipal do terreno, e a ideia foi aceita para discussão pela gestão municipal vigente (20092012). Acredita-se que o interesse municipal se deu pelo fato de a região fazer parte de um projeto proposto no Plano de Governo da época, o Projeto Novo Centro, ${ }^{6}$ que surgiu a partir da percepção de urbanistas e gestores públicos da necessidade de revitalização da área central da cidade, compreendendo, dentre outras questões, a readequação de uso e ocupação da área (IPPUC, 2012). Com base nessa perspectiva, a ideia de construir uma praça em um terreno abandonado em uma região alvo das transformações propostas pelo projeto convergia as expectativas do poder público e da sociedade, neste caso representada pela Ciclolguaçu.

Foram realizadas reuniões para discutir o projeto da praça, que ficou sob a responsabilidade de arquitetos do Instituto de Pesquisa e Planejamento Urbano de Curitiba (IPPUC), contando com a participação de membros da associação. Depois que uma planta foi elaborada, a prefeitura, a princípio, realizaria as ações e entregaria a obra à população no período do Fórum Mundial da Bicicleta, ${ }^{7}$ cuja terceira edição ocorreu em Curitiba entre os dias 13 e 16 de fevereiro de 2014.

No entanto, a construção da praça não aconteceu no tempo esperado. Os processos licitatórios públicos tendem a ser morosos, pois necessitam passar por instâncias diferentes e, por vezes, burocráticas. Além disso, os acontecimentos que ocorriam na cidade de Curitiba nesse período, dentre eles a realização da Copa do Mundo da FIFA, dificultaram a concretização das obras, que acabaram atravessando gestões municipais.

Sobre isso, Patrício (2015, p. 1, grifo nosso) relata que:

Inicialmente houve uma abertura para o diálogo e a declaração de que a área citada fazia parte de um plano de recuperação de espaços públicos e seria, no futuro, revitalizada. Entretanto, o processo burocrático prometia ser lento e demorado por conta das restrições impostas pelas obras para a Copa do Mundo da FIFA e as eleições presidenciais. Em contrapartida, em fevereiro de 2014, Curitiba recebia 0 $3^{\circ}$ Fórum Mundial da Bicicleta, e parte das atividades se dariam próximas à praça.

\footnotetext{
5 De acordo com Teixeira (2016, p. 616-617), "falência é um processo de execução coletiva, ou um concurso de credores, no qual os bens do falido são arrecadados para uma venda judicial forçada, com a distribuição proporcional do resultado entre todos os credores. [...] promove o afastamento do devedor de suas atividades, [...] a gestão do negócio ficará a cargo do administrador judicial nomeado pelo juiz". Segundo o autor, "massa falida" é "o acervo que compreende o ativo (bens e créditos) e o passivo (débitos) do falido, que passa a ser gerido e representado pelo administrador judicial". No presente estudo, a massa falida diz respeito a um prédio de cerca de 20 andares, localizado ao lado da PBC, cuja construção encontra-se inacabada e com características de abandono. $O$ termo foi utilizado por um entrevistado da Prefeitura Municipal de Curitiba, quando se referiu ao prédio contíguo à praça.

60 objetivo consistia também em "criar novos atrativos, em parceria com a sociedade, fomentando setores econômicos e turísticos, proporcionando o retorno da função moradia" (IPPUC, 2012). A área prioritária de atuação do projeto foi a região do entorno do antigo Paço Municipal, que engloba as ruas Riachuelo e São Francisco.

7 Evento anual de cicloativismo. Sua edição inicial, em 2012, aconteceu em Porto Alegre, marcando o ano do atropelamento coletivo de ciclistas que participavam de uma bicicletada (Massa Crítica) na capital gaúcha (BRAND, 2016). Para a realização do evento, alguns princípios são adotados, como gratuidade da participação nas atividades, organização por trabalho voluntário e horizontal, autogestão e desenvolvimento por pessoas (e não empresas), livre de marcas registradas, etc.
} 
Santos (2012) afirma que a modernidade e as necessidades de globalização da economia fazem com que o poder público aceite uma ordem de prioridades que privilegiam alguns poucos atores, limitando a ação de outros, como pequenas empresas, instituições menos estruturadas e as próprias pessoas, o que 0 autor chama de espaços da racionalidade (principalmente econômica).

Enquanto os olhares estavam voltados para a racionalidade econômica e social hegemônica do momento na cidade, representada pela realização da Copa do Mundo da FIFA, o projeto da praça, que surgiu a partir de uma demanda populacional, direcionado a uma fração envelhecida do centro da cidade, acabou ficando, durante um período, fora da pauta prioritária de ação do poder público.

O Fórum teve como objetivo discutir questões de ciclomobilidade, mas também "resgatar ideias voltadas para o ser humano e espaços de convivência. Nós acreditamos que, ao usar a bicicleta não apenas como um meio de transporte, mas como meio de transformação, será possível alcançar uma mobilidade urbana sustentável de verdade" (BRAND, 2016). Dessa forma, as questões urbanas concretas e subjetivas problematizadas pelo Fórum Mundial da Bicicleta fizeram do evento um catalisador que reacendeu as discussões em torno da possibilidade de construção da PBC.

$\mathrm{Na}$ ocasião, o paredão de fundo do terreno onde seria futuramente construída a PBC recebeu uma pintura realizada por Mona Caron (Figura 3), artista suíça internacionalmente conhecida, cujos trabalhos estão frequentemente relacionados à arte urbana.

Figura 3 - Mural pintado por Mona Caron

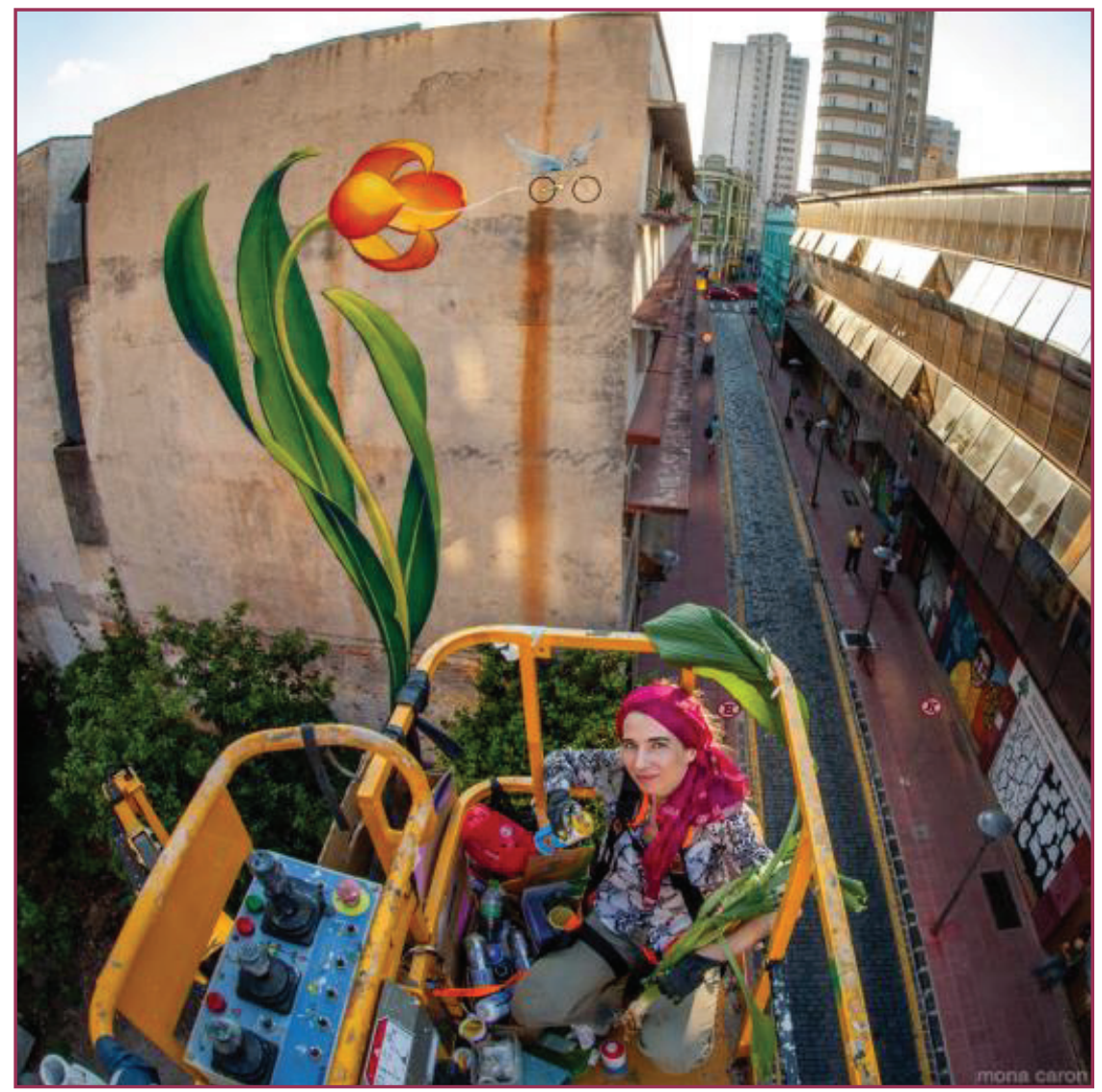

Fonte: Mona Caron, 2016 
Para a artista, o mural da PBC:

[...] anunciou o início de uma série de intervenções de base para recuperar e transformar fisicamente este canto muito negligenciado da rua, para refletir 0 desejo da comunidade por uma cidade mais habitável. [...] A imagem simples do mural simboliza o florescimento do ambiente urbano, que está dando à luz formas mais leves de pisar o solo urbano. A flor dramaticamente grande significou sentir como um rufar de tambores que revela, anticlimaticamente, apenas uma pequena bicicleta. A ideia é que apenas uma coisa simples, modesta, como promover 0 uso diário de bicicletas, pode, em última análise, ter grande impacto no ambiente urbano (MONA CARON, 2016, tradução nossa).

Pela forma como o Fórum se organizou, pelas discussões e ideias por ele promovidas e pelas dificuldades burocráticas encontradas quanto à implantação da praça a partir dos meios públicos, surgiu a ideia de que esse espaço poderia ser construído pela própria população, em regime de mutirão. A iniciativa constituiu uma adaptação criadora à realidade existente (SANTOS, 2012), contrapondo a racionalidade hegemônica econômica e social imposta pelo contexto, quando a prioridade era a realização da Copa do Mundo na cidade.

A ideia de construção coletiva da praça representava uma contrairracionalidade (SANTOS, 2012), pois a área não apresentava nenhum potencial de uso hegemônico, tanto pela dimensão reduzida como por localizar-se ao lado de uma massa falida, uma área "opaca" do ponto de vista econômico/imobiliário. No âmbito social, os ciclistas na cidade podem ser considerados minoria quando comparados ao elevado número de motoristas e automóveis que circulam no ambiente urbano, o que pode justificar o fato de eles serem os protagonistas dessa ação de construção coletiva da praça, a partir da realização de mutirões.

O presidente do Instituto de Pesquisa e Planejamento Urbano de Curitiba (IPPUC), Sérgio Póvoa Pires, afirmou que (PMC, 2014):

Uma licitação é sempre demorada. Aqui, encontramos uma alternativa, fazendo algo inédito em termos de parceria do poder público com a comunidade. Assim, viabilizamos um novo espaço de convivência que já está revitalizando o centro da cidade de um jeito inusitado.

Uma parceria até então inédita na cidade foi estabelecida entre administração pública e comunidade, representada pelos cicloativistas. A PMC se encarregaria de viabilizar as condições mínimas necessárias para o início das obras (cessão do terreno, ajustes com maquinaria especializada) e, posteriormente, a comunidade se encarregaria de realizar 0 restante da construção coletivamente.

Então, o projeto, que havia sido iniciado de forma interna pelo IPPUC e Ciclolguaçu, passa a ser discutido abertamente com a população interessada nas reuniões que aconteciam na Bicicletaria Cultural. A divulgação era realizada via internet (e-mails, redes sociais, páginas da web das instituições envolvidas) e também por cartazes colados na região do entorno.

Mesmo abertas para quem quisesse participar, as reuniões e a condução de todo 0 processo de maneira geral, que se deu a partir de um trabalho colaborativo, eram centradas em alguns atores específicos, particularmente aqueles que estiveram envolvidos na organização do Fórum Mundial da Bicicleta, integrantes da Bicicletaria Cultural e Ciclolguaçu.

A partir das discussões promovidas, um modelo final de projeto foi elaborado. Alguns elementos do projeto inicial desenvolvido pelo IPPUC não puderam ser mantidos, pois fugiam 
ao alcance de uma construção baseada no princípio do mutirão, uma vez que exigiam materiais e conhecimentos mais especializados.

Ficou acordado que alguns materiais armazenados nos depósitos das Secretarias Municipais seriam disponibilizados para a construção da futura praça. Nos relatos, também foi citada a participação de uma construtora particular que operava empreendimentos na região do entorno. Essa empresa disponibilizou materiais e contribuiu financeiramente para 0 andamento da construção da praça. Além da parceria estabelecida entre Ciclolguaçu e órgãos municipais (especialmente Secretarias de Obras, Meio Ambiente, Trânsito e IPPUC), houve colaboração do administrador judicial do prédio contíguo à praça e da Bicicletaria Cultural, além de pessoas voluntárias, não necessariamente ligadas a alguma instituição, que se interessaram pela ação.

Nessa fase inicial de idealização e planejamento da praça foram tomadas as seguintes ações: a) discussão e desenvolvimento do projeto; b) direcionamento horizontal das funções entre as pessoas envolvidas (a partir dos saberes e interesses de cada um); c) disponibilização, compra e arrecadação dos materiais necessários; e d) início da construção da praça, efetivamente.

Conforme menciona Santos (2012, p. 82), o espaço é formado por um conjunto indissociável de sistemas de objetos e sistemas de ações, os quais são resultantes de necessidades, naturais ou criadas (materiais, imateriais, econômicas, sociais, culturais, morais, afetivas). Para o autor, são essas necessidades que conduzem os homens a agir e levam a funções, que, "de uma forma ou de outra, vão desembocar nos objetos. Realizadas através de formas sociais, elas próprias conduzem à criação e ao uso de objetos, formas geográficas".

A ideia de intervir nesse pequeno espaço urbano a partir da implantação da praça articulou, direta ou indiretamente, esferas sociais diversificadas, as quais viam a possibilidade de conectar suas demandas e seus interesses à modificação do local. Para a Associação Ciclolguaçu, a praça corresponderia a um espaço concreto e também simbólico de representatividade da cultura da bicicleta na cidade, além de evidenciar o papel da ação cidadã, mostrando a possibilidade de construção de uma cidade mais humana e atuante. A Bicicletaria Cultural, por sua vez, compartilhando da visão da associação, contaria também com um marco da cultura da bicicleta em frente à sua sede, na iminência de atrair mais pessoas que têm afinidade com a temática para o local, dando-Ihes a oportunidade de conhecer e possivelmente usufruir de seus serviços. No âmbito das construtoras, as melhorias poderiam trazer valorização para a região e visibilidade para os empreendimentos no entorno. Os comerciantes próximos também ganhariam com a presença de mais pessoas no local, potenciais consumidores de seus produtos. Na esfera do poder público, a implantação do espaço seria de custo mínimo e uma região central subutilizada da cidade ganharia função.

Outros pontos ainda poderiam ser evidenciados, no entanto, o que se verifica é que o espaço, nesse caso o urbano, não é imparcial ou neutro, mas influenciado pelas ações e objetos que abriga e que se condicionam mutuamente, em profunda relação com o momento histórico, econômico, social e político vivido. Portanto, esses atores sociais, nas suas esferas e a partir de seus interesses específicos, contribuíram de diferentes formas e desenvolveram uma espécie de rede que possibilitou a idealização da praça. 


\subsection{A construção da PBC: fins de semana de mutirão}

Os "mutirões", como foram denominadas as ações concretas de construção da PBC, aconteceram em 2014, durante 21 fins de semana, reunindo cerca de 100 pessoas em cada uma dessas forças-tarefa (PATRICIO, 2015).

As reuniões de planejamento continuaram acontecendo na Bicicletaria Cultural e também eram abertas à participação de todos, mas agora tinham como objetivo a discussão da execução do projeto, o andamento da construção, os próximos passos a serem seguidos a cada mutirão, as atividades culturais de animação da praça, dentre outras questões.

Os mutirões aconteceram de modo a concluir diferentes etapas do processo. Nesses trabalhos, seria bem-vindo qualquer um que tivesse interesse em participar, ajudando na execução de um trabalho com que tivesse afinidade, fossem pedestres passando pela rua, pessoas que ficaram sabendo do movimento pelos meios de comunicação ou ainda por indicação dos próprios voluntários que participavam das ações.

Com o intuito de facilitar a movimentação dos voluntários que trabalhavam no local, cujo número aumentava gradativamente, e também de garantir sua segurança no espaço, a primeira quadra da Rua São Francisco foi fechada para o trânsito de automóveis nos fins de semana em que ocorriam os mutirões.

O planejado era que construção da praça fosse feita nos fins de semana, de maio a junho de 2014. No entanto, o processo acabou se estendendo por mais alguns meses, em função de condições climáticas, pois algumas tarefas não podiam ser realizadas em dias chuvosos, mas também devido à própria mão de obra de caráter voluntário, rotativa e nem sempre especializada. Diferentes pessoas participavam dos mutirões, e algumas tinham contato pela primeira vez com determinadas tarefas. Dessa forma, um tempo extra precisava ser disponibilizado para o ensino/aprendizagem de diversos trabalhos, pois o processo precisava ser repetido sempre que novos voluntários apareciam para colaborar, à medida que tomavam conhecimento e se interessavam pela construção da praça.

Havia um "núcleo duro", de cerca de 20 pessoas, que marcava presença quase todos os fins de semana. Esse grupo acabou tomando a frente da obra, e passou a encabeçar algumas linhas gerais, a partir do interesse e domínio de determinadas atividades. Essas pessoas mais assíduas geralmente orientavam, cada qual na sua especialidade, as que chegavam no decorrer do processo, conforme reforçam os relatos:

\footnotetext{
Teve naturalmente nesse processo, algumas pessoas que meio que se autocolocaram com mais disposição de puxar a coisa [...] então a gente começou a abrir várias frentes de ação (Integrante Ciclolguaçu 1).

[...] algumas pessoas que começaram desde, estavam ali desde ali de dentro, aí eu não sei como aconteceu, mas elas já tinham coisas que elas sabiam fazer muito bem que elas começaram a orientar nesses nichos (Voluntária 2).
}

Com relação à construção propriamente dita da praça, a maioria dos trabalhos ocorreu de forma simultânea: colocação de pedras, construção das calçadas e muros, construção do banco redondo, revitalização do muro histórico, instalação da iluminação, jardinagem, intervenções artísticas, instalação de paraciclos.

Segundo Gehl (2015, p. 23), "[...] as pessoas reúnem-se onde as coisas acontecem, e espontaneamente buscam outras pessoas", assim, para além dos mutirões, um movimento 
cultural periférico de uso e animação do espaço do entorno passou a acontecer paralelamente aos trabalhos de construção da praça. A primeira quadra da Rua São Francisco, fechada para os carros, tornou-se um polo de atividades culturais nos fins de semana, e isso ajudou a agregar e atrair pessoas para o espaço, funcionando como um "chamariz" de voluntários e pessoas para a rua. $^{8}$

As atividades abrangiam uma gama diversificada de linguagens e experiências: exibições de filmes e documentários, apresentações de música, teatro, dança, oficinas de culinária e malabarismo, mosaico, pintura, horta capilar, atividades infantis, jogos e brincadeiras e ações educativas referentes à ciclomobilidade na cidade.

Outras oficinas resultaram em elementos concretos da praça, a exemplo do mosaico, cujas produções foram usadas para recobrir o banco redondo de superadobe. Nas oficinas de pintura e estêncil, foram produzidos placas e desenhos distribuídos ao longo da praça e da rua, geralmente com mensagens simbólicas e educativas sobre a cidade, numa perspectiva que remete à sua humanização, e sobre o uso da bicicleta: "cidades para pessoas", "mais amor, menos motor", "recrie sua cidade", "somos todos pedestres", são exemplo de frases elaboradas.

Havia um número significativo de bicicletas circulando pela região ou estacionadas, presas aos postes localizados ao longo da Rua São Francisco. De crianças a idosos, ciclistas ou não, voluntários que trabalhavam na construção da praça compartilhavam o espaço com cantores, pintores, fotógrafos, músicos e atores. Curiosos também apareciam, interessados em entender o que estava sendo desenvolvido naquele espaço, também frequentado por moradores de rua e mendigos.

A praça, mesmo ainda em desenvolvimento, e a Rua São Francisco tornaram-se espaços de convivência, de confraternização, de troca de experiências e saberes, em um ambiente de convívio diversificado entre pessoas de diferentes classes sociais e faixas etárias, reunindo distintas formas de pensar e viver. Mas esse processo não ocorreu integralmente de forma harmoniosa, pois alguns moradores da região e funcionários/alunos de uma escola próxima não eram favoráveis às ações ali desenvolvidas, e por vezes se mostraram incomodados com a movimentação no local.

Rechia (2006, p. 91) relata que "[...] a cidade significa também a relação do sujeito consigo mesmo, com o outro e com o lugar onde vive [...]" e acrescenta a importância da relação entre o cotidiano na cidade e os lugares abertos/públicos, tais como a rua, parques e praças na cidade, considerados "[...] o próprio pulsar da vida urbana" (RECHIA, 2006, p. 95). Estes são lugares do encontro, que promovem a convivência, seja ela conflituosa, harmônica, ampla ou limitada, com a diversidade, com aquele que é estranho, diferente.

Ressalta-se assim a importância da sociedade e do "elemento" humano, animando as formas espaciais e lhes atribuindo um conteúdo. A ação humana no espaço público é uma forma de sinalizar conteúdos práticos da vida social urbana. No caso da construção da praça, essa ação que transformou o espaço aconteceu pela via das atividades no âmbito do lazer. Os diferentes interesses culturais do lazer, principalmente os propostos por Dumazedier (1980), puderam ser identificados durante o processo, sempre de forma complementar um ao outro, e não isolados (interesses físico-esportivos, artísticos, sociais, manuais e intelectuais).

8 A São Francisco é uma das ruas mais antigas da cidade, muito famosa por seu aspecto sombrio e até, de certa forma, perigoso, em função de atividades constantes de consumo e tráfico de drogas. Era uma rua na qual as pessoas evitavam circular antigamente. 
Mesmo que alguns trabalhos ainda não estivessem concluídos, após aproximadamente cinco meses de construção o espaço estava praticamente finalizado. A Praça de Bolso do Ciclista de Curitiba foi inaugurada em 22 de setembro de 2014, exatamente no Dia Mundial Sem Carro. Na cerimônia, estavam presentes autoridades como o Prefeito da cidade, membros de secretarias municipais e cicloativistas. Notícias veiculadas pela agência de notícias da PMC e de um jornal local divulgaram o evento de inauguração:

Curitiba celebrou o Dia Mundial Sem Carro, nesta segunda-feira (22), com a inauguração da Praça de Bolso do Ciclista, espaço construído pela comunidade com 0 apoio de várias secretarias municipais, numa área na região central cedida pela Prefeitura. Mais que uma obra física, a nova praça foi saudada como um marco da cultura de parceria entre sociedade e poder público. "A Praça de Bolso do Ciclista é um bem imaterial da cidade. A palavra que define este lugar é atitude, $\mathrm{e}$ é somente dessa maneira, com a mobilização de todos, que podemos transformar a nossa sociedade", disse o prefeito Gustavo Fruet.

[...] Ao longo dos três meses de construção, a praça já sediou inúmeros eventos culturais e está mexendo com a comunidade. "Foi um sonho que transformamos em realidade com a colaboração de muita gente", disse Vinícius Brand, coordenador da Ciclolguaçu. "A praça é um ente social que transforma as pessoas: os que a frequentam, os que a construíram e até a vizinhança da Rua São Francisco, que nos apoiou e também é amiga desta iniciativa. Acima de tudo, comprova que a bicicleta é um elemento humanizador e agregador dentro do espaço urbano", comemorou o cicloativista Julian Irusta (PMC, 2014, grifo nosso).

"Esta praça simboliza a transformação e a humanização de uma cidade por seus diversos atores, inclusive o poder público. É um ato de respeito pelos cidadãos que tiveram materializada a sua vontade", destacou o secretário municipal de Meio Ambiente, Renato Lima (RIC MAIS, 2014).

\section{CONSIDERAÇÕES FINAIS}

As cidades, mesmo com características de fragmentação, segregação e especialização do espaço urbano, ainda mantêm ambientes propícios para restabelecer e superar esse processo. A cidade muitas vezes é caótica, mas é também lugar de realização da vida, de lutas e resistências, e uma das brechas nesse tumultuado meio urbano são os espaços de encontro e sociabilidade, que podem manter a cidade viva e pulsante.

A PBC, fruto de uma microrrevolução coletiva e um marco da cultura da bicicleta na cidade de Curitiba, constitui umas dessas brechas, em várias dimensões. Esse pequeno espaço foi criado para promover a convivência em um ambiente denso de pessoas e edificações; remete ao uso da bicicleta como uma alternativa modal mais humanizada e sustentável à predominância do deslocamento por automóvel; foi concretizado por meio de mecanismos inéditos de atuação conjunta de diferentes esferas sociais (privadas, públicas, associativas), a partir da atuação em rede; e seu processo de construção caminhou lado a lado com um movimento cultural intenso.

Outras questões urbanas, políticas, econômicas, sociais e culturais significativas puderam ser colocadas em discussão a partir dessa experiência, como a dimensão comunitária e sua perspectiva de ação na cidade, as estratégias que viabilizam essas experiências, a representatividade popular e a participação nas decisões e no diálogo com o poder público, a minimização das possíveis distâncias entre gestão e sociedade quando esta se organiza por meio de associações. 
O protagonismo de diferentes atores sociais, mas principalmente do cidadão, e as táticas utilizadas no processo de construção da PBC buscaram qualificar um local anteriormente subutilizado, visando a uma melhor qualidade de vida urbana. Acredita-se que quanto maior o envolvimento dos sujeitos com determinados espaços públicos, maior a probabilidade de as pessoas os apropriarem de fato e desenvolverem um sentimento de pertencimento. Além dos aspectos práticos, como manutenção, segurança, acessibilidade e iluminação, pode-se desenvolver uma identidade com o lugar a partir das experiências significativas nele vividas.

Uma experiência de trabalho, cujo "produto final" foi a Praça de Bolso do Ciclista, configurouse também como experiência na dimensão do lazer, a partir da vivência simultânea da cidade, do trabalho coletivo, do contato com o "estranho", dos conteúdos culturais do lazer, de forma espontânea e com base na possibilidade da escolha. O processo não aconteceu inteiramente sem conflitos, tensões ou divergências, uma vez que opiniões, visões e formas de conceber o espaço nem sempre foram unânimes, mas houve igualmente a oportunidade do aprendizado gerado por essas situações.

Os processos educacionais, formais ou informais, para o uso harmonioso do espaço e a necessidade de políticas públicas que garantam manutenção básica e segurança também são importantes para que o local possa se tornar um espaço agradável de convivência.

O direito à obra e à apropriação está implicado no direito à cidade, que se manifesta como forma superior dos direitos (à liberdade, à individualização na socialização, ao habitat e ao habitar) e pôde ser exercido a partir do processo de construção da Praça de Bolso do Ciclista de Curitiba, vivido enquanto uma experiência de lazer na cidade.

\section{REFERÊNCIAS}

BLAKE, Alison. Pocket Parks. In: MARYMAN, Brice; ROTTLE, Nancy. Green Futures Toolkit: a resource guide for designing Seattle's green network. Landscape Architecture: Washington: University of Washington. College of Architecture and Urban Planning Landscape Architecture, 2006. p.163-168. Disponível em: <http://depts. washington.edu/open2100/toolkit.pdf>. Acesso em: 14 dez. 2016.

BRAND, Vinícius Cubas. [Divulgação]. In: FÓRUM MUNDIAL DA BICICLETA, 3. 2014. Curitiba. Disponível em: <https://www.catarse.me/pt/fmb2014>. Acesso em: 15 dez. 2016.

BRASIL. Conselho Nacional de Saúde. Resolução n. 466, de 12 de dezembro de 2012. Diário Oficial da União, Poder Legislativo, Brasília, DF, 13 jun. 2013. Disponível em: <http://www.planalto.gov.br/ ccivil/Decreto-Lei/1965-1988/Del0464.htm>. Acesso em: 14 dez. 2016.

DUMAZEDIER, Joffre. Valores e conteúdos culturais do Lazer. São Paulo: SESC, 1980.

GEHL, Jan. Cidades para pessoas. 3. ed. São Paulo: Perspectiva, 2015.

GÜNTHER, Hartmut et al. Multimétodos. In: CAVALCANTI, Sylvia; ELALI, Gleice Azambuja (Org.).

Temas básicos em psicologia ambiental. Petrópolis, RJ: Vozes, 2011. p. 239-249.

IPPUC. INSTITUTO DE PESQUISA E PLANEJAMENTO URBANO DE CURITIBA. Revitalização Rua São Francisco (Cartilha). Curitiba: Prefeitura Municipal de Curitiba, 2012.

LEFEBVRE, Henri. 0 direito à cidade. São Paulo: Centauro, 2001. 
MINAYO, Maria Cecília de Souza (Org.); DESLANDES, Suely Ferreira; CRUZ NETO, Otávio; GOMES, Romeu. Pesquisa social: teoria, método e criatividade. 30. ed. Petrópolis, RJ: Vozes, 2011.

MONA CARON. Bike Flower in Curitiba. Disponível em: <http://www.monacaron.com/artivism/bikeflower-curitiba>. Acesso em: 15 dez. 2016.

PAGNONCELLI, Hermínio Antônio. Pocket park em Curitiba. 2012. 86 f. Trabalho de Conclusão de Curso (Graduação em Arquitetura e Urbanismo) - Universidade Federal do Paraná, Curitiba, 2012.

PATRICIO, Luis Cláudio Brito. Praça de Bolso do Ciclista: uma construção comunitária. In: CONGRESSO BRASILEIRO DE TRANSPORTE E TRÂNSITO, 20. 2015. Santos: Associação Nacional de Transportes Públicos (ANTP), 2015. Disponível em: <http://www.antp.org.br/ 5dotSystem/ download/dcmDocument/2015/06/15/7C70735A-0300-4B44-93BB-9EC21EBE9308.pdf>. Acesso em: 14 dez. 2016.

PMC. PREFEITURA MUNICIPAL DE CURITIBA. Parceria entre Prefeitura e comunidade torna realidade a Praça de Bolso do Ciclista. Curitiba: Agência de Notícias da Prefeitura Municipal de Curitiba, 22 set. 2014. Disponível em: <http://www.curitiba.pr.gov.br/noticias/parceria-entre-prefeiturae-comunidade-torna-realidade-a-praca-de-bolso-do-ciclista/34189>. Acesso em: 15 dez. 2016.

RECHIA, Simone. O pulsar da vida urbana: o espaço, o lugar e os detalhes do cotidiano. In: CARVALHO, João Eloir (Org.). Lazer no espaço urbano: transversalidade e novas tecnologias. Curitiba: Champagnat, 2006. p. 91-102.

RIC MAIS. Praça de Bolso do Ciclista é inaugurada em Curitiba. Curitiba: 22 set. 2014. Disponível em: <http://pr.ricmais.com.br/diversao-e-arte/noticias/praca-de-bolso-do-ciclista-e-inaugurada-emcuritiba/>. Acesso em: 15 dez. 2016.

SANTOS, Milton. A natureza do espaço. 5. ed. São Paulo: Universidade de São Paulo, 2012.

TEIXEIRA, Tarcisio. Direito empresarial sistematizado: doutrina, jurisprudência e prática. 5. ed. São Paulo: Saraiva, 2016.

WEISHOF, Noah. Pocket park: um olhar sobre o vazio esquecido. 2014. $147 \mathrm{f}$. Trabalho de Conclusão de Curso (Graduação em Arquitetura e Urbanismo) - Universidade Federal do Paraná, Curitiba, 2014.

YIN, Robert K. Estudo de caso: planejamento e métodos. 5. ed. Porto Alegre: Bookman, 2015. 